bên sau khi đặt stent nhánh chính, khả năng thất bại hoặc khó khăn khi đưa lại dây dẫn từ nhánh chính qua mắt stent vào nhánh bên rất cao. Trong nghiên cứu của Carinax cũngcho thấy tổn thương Medina 1.1.1; Medina 1.0.1 và Medina 0.1.1 thường gặp nhiêu nhất [8], Góc chia nhánh $\alpha$ tạo bởi đoạn xa nhánh chính và nhánh bên cũng là một trong những yếu tố quan trọng trong việc lựa chọn chiến lược can thiệp cho tổn thương chỗ chia nhánh động mạch vành. Ở nghiên cứu của chúng tôi, góc chia nhánh $\alpha<70^{\circ}$ gặp chủ yếu với tỷ lệ là $84,4 \%$. Thang điểm Syntax là một công cụ cho điểm để đánh giá mức độ phức tạp của tổn thương động mạch vành trên chụp mạch, góp phần giúp các bác sĩ lựa chọn chiến lược điều trị cho bệnh nhân. Trong đa số các trường hợp, khi điểm Syntax $>32$ thì sẽ ưu tiên lựa chọn phẫu thuật bắc cầu nối chủ vành (CABG) cho bệnh nhân, vì các nguy cơ rủi ro khi can thiệp cao. Trong nghiên cứu của chúng tôi, điểm Syntax trung bình là $18 \pm 6,3$ vàtỷ lệ bệnh nhân có điểm Syntax < 23 chiếm đa số $(80,85 \%)$, phù hợp với can thiệp động mạch vành qua da. Có 3 bệnh nhân $(2,13 \%)$ có điểm Syntax $>32$.

\section{KẾT LUÂN}

- Nam gặp nhiều hơn nữ, vớituổi lớn hơn 60 gặp chủ yếu và tăng huyết áp là yếu tố nguy cơ tim mạch gặp nhiều nhất.

- Tổn thương chỗ chia nhánhđộng mạch vành thường gặp nhất trên động mạch liên thất trước và tổn thương phần lớn thuộc các nhóm tổn thương phức tạp (Medina 1.1.1, Medina 1.0.1 và Medina 0.1.1). Góc chia nhánh $\mathrm{a}<70^{\circ}$, và điểm Syntax $<23$.

\section{TÀI LIẸU THAM KHẢO}

1. Nguyễn Lân Việt (2015), Thực hành bệnh tim mạch, Nhà xuất bản Y học.

2. Louvard Y. và Medina A. (2015). Definitions and classifications of bifurcation lesions and treatment. EuroIntervention. 2015;11:V23-V26.

3.Louvard Y., Thomas M., Dzavik V., et al. Classification of coronary artery bifurcation lesions and treatments: Time for a consensus! Catheterization \& Cardiovascular Interventions 2008; Pages 175-183.

4. Medina A, Suárez de Lezo J, Pan M. (2006), [A newclassification coronarybifurcationlesions].Rev Esp Cardiol. 2006 Feb;59(2):183 - 184.

5. Lassen JF, Holm NR, Stankovic G, et al. Percutaneous coronary intervention for coronary bifurcation disease: Consensus from the first 10 years of the european bifurcation club meetings. EuroIntervention. 2014;545-560.

6. Zhang J.-J., Ye F., Xu K. và cộng sứ. (2020). Multicentre, randomized comparison of two-stent and provisional stenting techniques in patients with complex coronary bifurcation lesions: the DEFINITION II trial. Eur Heart J, 41(27), 2523-2536.

7. Bùi Long (2019), Nghiên cứu kêt quá điêu trị can thiệp bềnh nhân hôi chứng động mach vành cấp bằng stent phủ thuốc có polymer tự tiêu, Luận án tiến sĩ Y học, Học viện Quân Y.

8. Briguori C.,, Donahue M., Visconti G. và cộng sự. (2017). Coronary artery bifurcation narrowing treated by Axxess stent implantation: The CARINAX registry. Catheter Cardiovasc Interv, 89(4), E112-E123.

\title{
ĐÁNH GIÁ KẾT QUẢ PHẪU THUÂT CẮT XƯƠNG ĐẦU DƯỚI XƯƠ'NG CÁNH TAY ĐIỀU TRI BIẾN DẠNG KHUỶU VẸO TRONG
}

\section{TÓM TẮT}

Mục tiêu: Cắt xương hình chêm bên ngoài là phương pháp điều trị thường được áp dụng để chỉnh biến dạng khuỷu vẹo trong hiện nay. Kết xương nhằm cố định ổ cắt xương, duy trì kết quả nắn chỉnh đến khi liền xương. Kỹ thuật căt xương hình chêm, cố định bằng hai vít + buộc néo ép số 8 của French là đơn giản, dễ thực hiện và an toàn. Đối tượng và phương pháp: 63 bệnh nhân (BN) biến dạng khuỷu

*Bệnh viện Đa khoa Mê Linh, HN

**Trướng Đai hoc Y Hà Nôi

Chịu trách nhiệm chính: Đỗ Viết Tuyến

Email: Doviettuyenvn@gmail.com

Ngày nhận bài: 5/5/2021

Ngày phản biện khoa học: 7/6/2021

Ngày duyệt bài: 25/6/2021

\section{Đỗ Viết Tuyến*, Đào Xuân Tích**}

vẹo trong sau gãy trên trên đâu dưới xương cánh tay,

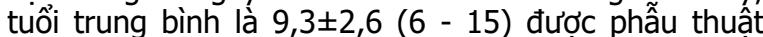
cắt xương hình chêm bên ngoài để chỉnh trục, thực hiện trong thời gian từ $6 / 2015$ đến tháng $12 / 2019$. Kểt quả: Theo rõi xa được 52/63( $82,5 \%)$ với thời gian trung bình là $44,8+11,1$ tháng (21- 82 tháng). Kết quả xa theo tiêu chuân của Ippolito: 33 bệnh nhân có kết quả tốt, 14 kết quả khá và 5 BN kết quả kém. Kết luâan: Chúng tôi cho rằng phương pháp French cải biển điều trị biến dang khuỷu vẹo trong thật sự đơn giản và hiệu quả điều trị tốt cả về thẩm mỹ் và chức năng.

Tư khóa: Biến dạng khuỷu vẹo trong, cắt xương hình chêm.

\section{SUMMARY \\ ASSESSMENT OF THE RESULTS OF DISTAL HUMERUS OSTEOTOMY TREATMENTING}




\section{CUBITUS VARUS DEFORMITY}

Aim: Lateral closed wedge (LCW) osteotomy is a commonly accepted method for the correction of the cubitus varus deformity. The fixation of osteotomy is required to prevent loss of correction achievedtill the union is achieved.. The fixation of the osteotomy by the twoscrew and figure of eight wire is commonly technique to maintain the peroperatively achieved correction. In this studythe fixation was supplemented byplaster. Materials and methods: Sixty three patients of the cubitus varus deformity following of the distal humeral fracture wereoperated by LCW (lateral condylar wedge) osteotomy during June 2016 to December 2019. The mean age of the patients at the time of corrective surgerywas $9,3 \pm 2,6$ (range 615 years). The osteotomy was fixed by two screws with figure of eight tension band wire between them. Result: Examination far results in 52 patients $(82,5 \%)$, the mean follow-up period was $44,8+11,1$ monts (range, 21- 82 months). The far results were assessed as per Ipollito criteria. 33 patients showed excellent results and 14 patients showed good results and 5patients showed poor results. Conclusion: We believe that the modified French method of treating cubitus varus deformity of the elbow is really simple and gives good treatment effect in both cosmetically and function.

Key words: Cubitus varus deformity, lateral condylar wedge osteotomy

\section{I. ĐĂT VẤN ĐỀ}

Biến dạng khuỷu vẹo trong (cubitus varus) là một biến chứng thường gặp sau gãy xương ở đầu dưới xương cánh tay ở trẻ em. Nguyên nhân sớm của biến chứng này là do nắn chỉnh không hết di lệchcòn di lệch gấp góc,di lệch xoay trong quá mức của lồi cầu ngoài; nguyền nhân muộn là do hoại tử hoặc kém phát triển của lồi cầu trong [1]. Di lệch mở góc vào trong là biến dạng có vai trò quyết định, bên cạnh đó di lệch xoay trong cũng góp một phần quan trọng. Nhiều kỹ thuật cắt xương ở đầu dưới xương cánh tay để chỉnh trục xương đã được đề xuất. Phương pháp cắt xương mở hình chêm ở thành trong dễ dẫn đến mất vững khớp khuỷu, khó cố định và có nguy cơ tổn thương TK trụ cao. Cắt xương hình chêm đáy ở thành ngoài là phương pháp đã được thực hiện từ lâu và an toàn. Điều còn tranh luận là chọn phương pháp cố định nào sau cắt xương để cốđịnh ổ cắt xương vững hơn và ít nguy cơ biến chứng hơn.[1], [2].

French đề xuất kỹ thuất cắt tam giác chêm xương ở thành ngoài,và cố định bằng 2 vít kết hợp với buộc néo ép số 8 . Bellemore đã cải biên kỹ thuật của cắt xương của French bằng cách giữ lai vỏ xương ở thành trong còn dính cốt mạc, chỉ bẻ gãy rồi sau đó kết xương theo kỹ thuật giống như French đã mô tả [3]. Chúng tôi đã áp dụng kỹ thuật trên để điều trị cho 63 trẻ em tại Bệnh viện Chỉnh hình phục hồi chức năng tỉnh Ninh Bình.Nhằm rút kinh nghiệm và nâng cao chất lượng điều trị biến dạng khuỷu vẹo trong ở trẻ em, chúng tôi nghiên cứu đề tài: "Đánh giá kết quả điều trị biến dạng khuỷu vẹo trong bằng phẫu thuật căt xương chinh trục" nhằm mục tiêu: Đánh giá kết quả điều trị biến dạng khuỷu vẹo trong bằng phẩu thuật cắt xương chinh trục theo kỹ thuật French cải biên.

\section{II. ĐỐI TƯợNG VÀ PHƯƠNG PHÁP NGHIÊN CỨU}

2.1. Đối tượng nghiên cứu: Gồm $63 \mathrm{BN}$ có biến dạng khuỷu vẹo trong sau gãy đầu dưới xương cánh tay, gồm có 12 nữ (19\%) và 51 nam (81\%). Khuỷu vẹo trong ở tay phải là $26 \mathrm{BN}$ $(41,3 \%)$, tay trái là $37 \mathrm{BN}(58,7 \%)$. Tuổi trung bình của $B N$ ở thời điểm gãy là 6 (4-9), thời điểm mổ là $9,3 \pm 2,6(6$ - 15). Biên độ gấp duỗi

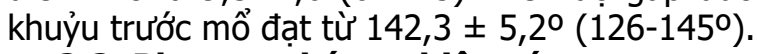

\subsection{Phương pháp nghiên cứu}

- Các bệnh nhân được điều trị phẫu thuật cắt xương chinh trục và kết xương theo phương pháp French cải biên trong thời gian từ tháng $6 / 2015$ đến 12/2019. Trước khi cắt xương, tiến hành khoan và bắt 2 vít song song với hai cạnh của chêm xương và sau khi cắt thì buộc néo ép số 8 bằng dây thép để đích cố định ổ cắt xương. Sau mổ tăng cường máng bột cánh bàn tay 3-4 tuần.

Khớp khuỷu sau phấu thuật tạo hình được khám và đánh giá so với bên lành:

+ Đo góc cánh cẳng tay trên phim $X$ quang chụp khớp khuỷu tư thế thẳng 2 bên.

+Tình trạng chênh lệch hơn $10^{\circ}$ so với bên lành và những phàn nàn của bệnh nhân và cha mẹ được coi là yếu tố để chỉ định phẫu thuật.

+ Các BN được tái khám mỗi tháng một lần trong vòng 6 tháng, chụp phim $X$ quang khớp khuỷutại các thời điểm sau mổ 1,3,6 và 12 tháng để đánh giá sự duy trì kết quả chỉnh trục đạt được sau mổ.

+ Đánh giá kết quả xa theo tiêu chuẩn ảa Ipolito.

Tiêu chuẩn đánh giá kết quả chức năng theo Ippolito (1990)[4 ]

\begin{tabular}{|c|c|c|c|}
\hline \multirow{2}{*}{ Tiêu chí đánh giá } & \multicolumn{3}{|c|}{ Kết quả } \\
\cline { 2 - 4 } & Tốt & Khá & Xấu \\
\hline Liền xương & $\begin{array}{c}\text { Liền } \\
\text { xương }\end{array}$ & $\begin{array}{c}\text { Liền } \\
\text { xương }\end{array}$ & $\begin{array}{c}\text { Liền } \\
\text { xương }\end{array}$ \\
\hline Góc cánh cằng tay & $>0^{\circ}$ & $<0^{\circ}$ & $<0^{\circ}$ \\
\hline $\begin{array}{c}\text { Chênh lệch góc cánh } \\
\text { cằng tay 2 bên }\end{array}$ & $<10^{\circ}$ & $<10^{\circ}$ & $>10^{\circ}$ \\
\hline $\begin{array}{c}\text { Biên độ gấp duỗi } \\
\text { khuỷu }\end{array}$ & $\begin{array}{c}\text { Giảm } \\
<10^{\circ}\end{array}$ & $>10^{\circ}$ & $>10^{\circ}$ \\
\hline
\end{tabular}




\section{KẾT QUẢ NGHIÊN CỨU}

\section{1.Đăc điểm biến dạng veo khuỷu}

Bảng 3.1. Kết quả đo lâm sảng góc cánh cẳng tay 2 bên trước mổ. ( $n=63)$

\begin{tabular}{|c|c|c|c|}
\hline Nhóm tuối & Góc cánh căng tay bên vẹo & Góc cánh căng tay bên lành & $\mathbf{P}$ \\
\hline 6 tuổi & $\begin{array}{c}-17,7 \pm 3,3(-21,5-(-11,2)) \\
\text { Trung vị: }-18,5\end{array}$ & $\begin{array}{c}7,6 \pm 0,4(7,0-8,0) \\
\text { Trung vị: } 7,5\end{array}$ & $<0,05$ \\
\hline 7 tuổi & $\begin{array}{c}-16,0 \pm 3,9(-27-(-12,8)) \\
\text { Trung vị: }-15,2\end{array}$ & $\begin{array}{c}8,1 \pm 0,3(8,0-9,0) \\
\text { Trung vị: } 8,0\end{array}$ & $<0,05$ \\
\hline 8 tuổi & $\begin{array}{c}-16,8 \pm 4,6(-25-(-11)) \\
\text { Trung vị: }-15,9\end{array}$ & $\begin{array}{l}8,2 \pm 0,3(8,0-9,0) \\
\text { Trung vị: } 8,1\end{array}$ & $<0,05$ \\
\hline 9 tuổi & $\begin{array}{l}-16,4 \pm 2,5(-20-(-12,4)) \\
\text { Trung vị: }-17,0\end{array}$ & $\begin{array}{l}9,1 \pm 0,4(9,0-10,0) \\
\text { Trung vị: } 9,2\end{array}$ & $<0,05$ \\
\hline 10 tuổi & $\begin{array}{c}-20,1 \pm 4,5(-25,4-(-13,8)) \\
\text { Trung vị: }-21,3\end{array}$ & $\begin{array}{c}9,1 \pm 0,4(9,0-10,0) \\
\text { Trung vị: } 9,2\end{array}$ & $<0,05$ \\
\hline 11 tuổi & $\begin{array}{c}-17,1 \pm 3,9(-26,2-(-12,5)) \\
\text { Trung vị: }-16,8\end{array}$ & $\begin{array}{c}9,5 \pm 0,4(9,0-10,0) \\
\text { Trung vị: } 9,5\end{array}$ & $<0,05$ \\
\hline 12 tuổi & $\begin{array}{c}-15,6 \pm 1,0(-16,5-(-14.5)) \\
\text { Trung vị: }-15,8\end{array}$ & $\begin{array}{c}10,3 \pm 0,3(10,0-11,0) \\
\text { Trung vị: } 10,5\end{array}$ & $<0,05$ \\
\hline 13 tuổi & $\begin{array}{c}-13,9 \pm 0,7(-14,4-(-13,4)) \\
\text { Trung vị: }-13,9\end{array}$ & $\begin{array}{l}10,2 \pm 0,5(10,0-11,0) \\
\text { Trung vị: } 10,2\end{array}$ & $<0,05$ \\
\hline 14 tuổi & $\begin{array}{c}-17,0 \pm 3,5(-21,0-(-14,5)) \\
\text { Trung vị: }-15,5\end{array}$ & $\begin{array}{c}11,1 \pm 0,6(11,0-12,0) \\
\text { Trung vị: } 11,5\end{array}$ & $<0,05$ \\
\hline 15 tuổi & $\begin{array}{c}-16,4 \pm 1,4(-18-(-15,3)) \\
\text { Trung vị: }-16,0\end{array}$ & $\begin{array}{c}11,5 \pm 0,7(11,0-12) \\
\text { Trung vị: } 11,8\end{array}$ & $<0,05$ \\
\hline $\begin{array}{l}\text { Giá trị trung } \\
\text { bình chung }\end{array}$ & $\begin{array}{c}-16,9 \pm 3,6(-27-(-11)) \\
\text { Trung vị: }-16,5\end{array}$ & $\begin{array}{l}8,9 \pm 1,2(7-12) \\
\text { Trung vị: } 8,8\end{array}$ & $<0,05$ \\
\hline
\end{tabular}

- Có 34 BN (54\%) bị biến dạng xoay trong trên lâm sàng (góc xoay đo được TB là 9,30 $\pm 2,7^{0}\left(8,5-20^{\circ}\right)$.

- Có $16 \mathrm{BN}(25,4 \%)$ có khuỷu ưỡn (duỗi quá mức) so với tay lành, TB là $5,7^{0} \pm 1,4^{0}\left(5-10^{\circ}\right)$.

- Biên độ gấp khớp khuỷu trung bình là: $142,30^{\circ} \pm 5,20\left(126^{\circ}-145^{\circ}\right)$.

3.2. Kết quả khảo sát góc cánh cẳng tay trên $X$ quang qui ước.

Bảng 3.2. Kết quả đo trên phim X quang góc cánh căng tay 2 bên trước mô. ( $n=63$ ).

\begin{tabular}{|c|c|c|c|}
\hline Nhóm tuổi & $\begin{array}{l}\text { Góc cánh cắng tay bên biến } \\
\text { dang }\end{array}$ & $\begin{array}{c}\text { Góc cánh cắng tay TB bên } \\
\text { lành }\end{array}$ & $\mathbf{P}$ \\
\hline 6 tuổi & $\begin{array}{c}-17,7 \pm 3,4(-21,4-(-11)) \\
\text { Trung vị: }-18,5\end{array}$ & $\begin{array}{c}7,6 \pm 0,4(7,0-8,2) \\
\text { Trung vị: } 7,6\end{array}$ & $<0,05$ \\
\hline 7 tuổi & $\begin{array}{c}-16,1 \pm 1,2(-27-(-13) \\
\text { Trung vi: }-15,2\end{array}$ & $\begin{array}{c}8,1 \pm 0,2(7,8-8,4) \\
\text { Trung vi: } 8,2\end{array}$ & $<0,05$ \\
\hline 8 tuổi & $\begin{array}{l}-16,7 \pm 1,6(-25-(-11) \\
\text { Trung vị: }-15,5\end{array}$ & $\begin{array}{l}8,2 \pm 0,3(7,8-8,7) \\
\text { Trung vị: } 8,2\end{array}$ & $<0,05$ \\
\hline 9 tuổi & $\begin{array}{c}-16,5 \pm 2,6(-20-(-12,4) \\
\text { Trung vi! }-17,2\end{array}$ & $\begin{array}{l}9,1 \pm 0,3(8,5-9,4) \\
\text { Trung vị: } 9,2\end{array}$ & $<0,05$ \\
\hline 10 tuổi & $\begin{array}{c}-20,1 \pm 4,5(-25,5-(-13,8) \\
\text { Trung vị: }-21,4\end{array}$ & $\begin{array}{l}9,1 \pm 0,4(8,6-9,5) \\
\text { Trung vị: } 9,1\end{array}$ & $<0,05$ \\
\hline 11 tuổi & $\begin{array}{c}-17,1 \pm 3,8(-26-(-12,7) \\
\text { Trung vị: }-16,5\end{array}$ & $\begin{array}{c}9,5 \pm 0,4(8,8-9,8) \\
\text { Trung vị: } 9,6\end{array}$ & $<0,05$ \\
\hline 12 tuổi & $\begin{array}{c}-15,8 \pm 1,8(-17-(-14.5) \\
\text { Trung vị: }-15,75\end{array}$ & $\begin{array}{l}10,4 \pm 0,3(10-10,6) \\
\text { Trung vị: } 10,5\end{array}$ & $<0,05$ \\
\hline 13 tuổi & $\begin{array}{c}-14,0 \pm 0,7(-14,5-(-13,5) \\
\text { Trung vi! }-14,0\end{array}$ & $\begin{array}{c}10,1 \pm 0,4(9,8-10,4) \\
\text { Trung vị: } 10,1\end{array}$ & $<0,05$ \\
\hline 14 tuổi & $\begin{array}{c}-17,2 \pm 3,6(-21,3-(-15) \\
\text { Trung vị: }-15,3\end{array}$ & $\begin{array}{l}11,2 \pm 0,6(10,5-11,5) \\
\text { Trung vị: } 11,5\end{array}$ & $<0,05$ \\
\hline 15 tuổi & $\begin{array}{c}-16,3 \pm 1,5(-18-(-15) \\
\text { Trung vị: }-16\end{array}$ & $\begin{array}{l}11,5 \pm 0,6(10,8-12) \\
\text { Trung vị: } 11,8\end{array}$ & $<0,05$ \\
\hline Giá trị TB & $\begin{array}{c}-17,0 \pm 3,6(-27-(-11)) \\
\text { Trung vị: }-16,4\end{array}$ & $\begin{array}{l}9,0 \pm 1,1(7-12) \\
\text { Trung vị: } 8,8\end{array}$ & $<0,05$ \\
\hline
\end{tabular}


- Số đo góc cánh cẳng tay bên vẹo khuỷu trước mổ và bên lành theo từng nhóm tuổi khác nhau có ý nghĩa thống kê $(p<0,05)$.

- Ở nhóm 6 tuổi góc chênh lệch giữa 2 tay là lớn nhất.

- Ở nhóm 13 tuổi góc chênh lệch giữa 2 tay là nhỏ nhất.

\subsection{Kết quả điêu tri}

3.3.1. Kêt quả gân ( 3 tháng đâu)

- Diễn biến tại vết mô: Liên kỳ đâu có $60 \mathrm{BN}$ $(95,2 \%)$.Nhiễm khuẩn vết mổ nông $3 \mathrm{BN}$ (4,8\%).Không gặp biến chứng nhiễm khuẩn sâu, viêm xương.

3.3.2. Kết quả khảo sát góc $C$ - CT trên phim $X$ quang tại thời điểm 6 tháng

Bảng 3.3. Góc cánh cẳng tay (C-CT) trên phim Xquang sau mổ 6 tháng $(n=63)$

\begin{tabular}{|c|c|c|}
\hline Nhóm tuối & Góc C-CT bên mố (độ) & Góc C-CT bên lành (độ) \\
\hline 6 tuối & $3,5 \pm 5,1(-3,5-8,5)$ Trung vị: 7,0 & $8,0 \pm 0,4(7,2-8,4)$ Trung vị: 8,2 \\
\hline 7 tuối & $5,4 \pm 3,9(-3,0-9,0)$ Trung vị: 7,0 & $8,4 \pm 0,6(7,6-9,5)$ Trung vị: 8,5 \\
\hline 8 tuối & $5,3 \pm 5,5(-5,0-11,3)$ Trung vị: 7,0 & $8,2 \pm 0,4(7,5-9,0)$ Trung vị: 8,2 \\
\hline 9 tuối & $7,4 \pm 3,6(2,0-12,5)$ Trung vị: 6,5 & $9,3 \pm 0,5(8,8-10,2)$ Trung vị: 9,2 \\
\hline 10 tuối & $8,3 \pm 2,8(4,5-12,2)$ Trung vị: 8,7 & $9,3 \pm 0,7(8,5-10,2)$ Trung vị: 9,0 \\
\hline 11 tuối & $7,1 \pm 5,6(0,0-16,5)$ Trung vị: 8,0 & $9,7 \pm 0,5(10,0-10,3)$ Trung vị: 9,8 \\
\hline 12 tuối & $6,3 \pm 4,4(1,0-9,8)$ Trung vị: 8,0 & $11,1 \pm 0,5(10,5-11,5)$ Trung vị: 11,3 \\
\hline 13 tuối & $5,5 \pm 2,1(4,0-7,0)$ Trung vị: 5,5 & $10,8 \pm 0,6(10,3-11,2)$ Trung vị: 10,8 \\
\hline 14 tuối & $9,6 \pm 2,7(6,5-11,2)$ Trung vị: 11,0 & $11,8 \pm 0,7(11,0-12,3)$ Trung vị: 11,2 \\
\hline 15 tuối & $10,7 \pm 3,3(7,3-13,8)$ Trung vị: 11,0 & $11,7 \pm 0,6(11,0-12,2)$ Trung vị: 11,8 \\
\hline Giá trị trung bình chung & $6,4 \pm 4,5(-5-16,5))$ Trung vị: 7,0 & $9,2 \pm 1,3(7,2-12,3)$ Trung vị: 9,0 \\
\hline & \multicolumn{2}{|c|}{$\mathrm{P}<0,05$} \\
\hline
\end{tabular}

Số đo góc cánh cắng tay bên vẹo khuỷu sau mố 6 tháng và bên lành theo từng nhóm tuối khác nhau có ý nghĩa thống kê $(\mathrm{p}<0,05)$.

3.3.3. Kết quả xa. Có $52 / 63$ BN được theo dõi kết quả xa (82,5\%). Thời gian theo dõi TB là $44,8 \pm 11,1$ tháng (từ 21-82 tháng).

Bảng 3.4. Kêt quả khảo sát góc Cánh cằng tay trên phim X quang tại thời điểm kiểm tra xa $(n=52)$.

\begin{tabular}{|c|c|c|}
\hline Nhóm tuối & Góc C-CT kiếm tra xa (độ) & Góc C-CT tay lành (độ) \\
\hline 6 tuối & $3,2 \pm 5,2(-4,0-8,6)$ Trung vị: 6,5 & $8,3 \pm 0,4(7,5-8,5)$ Trung vị: 8,5 \\
\hline 7 tuối & $5,4 \pm 4,1(-3,5-9,0)$ Trung vị: 7,4 & $8,7 \pm 0,6(8,0-9,8)$ Trung vị: 8,8 \\
\hline 8 tuối & $4,1 \pm 6,5(-5,5-10,0)$ Trung vị: 7,2 & $8,5 \pm 0,7(7,8-9,5)$ Trung vị: 8,5 \\
\hline 9 tuối & $7,8 \pm 4,0(2,4-12,5)$ Trung vị: 6,5 & $9,6 \pm 0,5(9,6-10,5)$ Trung vị: 6,5 \\
\hline 10 tuối & $7,5 \pm 2,3(4,5-10,2)$ Trung vị: 8,0 & $9,4 \pm 0,4(9,0-10,0)$ Trung vị: 9,0 \\
\hline 11 tuối & $7,3 \pm 6,3(0,5-16,8)$ Trung vị: 8,5 & $9,9 \pm 0,6(9,0-10,5)$ Trung vị: 10,0 \\
\hline 12 tuối & $6,4 \pm 4,6(1,2-10,0)$ Trung vị: 8,0 & $11,4 \pm 0,5(10,8-11,8)$ Trung vị: 11,5 \\
\hline 13 tuối & $5,4 \pm 2,3(3,8-7,0)$ Trung vị: 5,4 & $11,0 \pm 0,7(10,5-11,5)$ Trung vị: 11,0 \\
\hline 14 tuối & $9,5 \pm 2,5(6,6-11,0)$ Trung vị: 11,0 & $11,8 \pm 0,8(11,0-12,5)$ Trung vị: 12,0 \\
\hline 15 tuối & 13,50 & $13^{0}$ \\
\hline Giá trị trung bình chung & $6,1 \pm 4,8(-5,5-16.8)$ Trung vị: 7,0 & $9,5 \pm 1,3(7,5-13,0)$ Trung vị: 9,2 \\
\hline & \multicolumn{2}{|c|}{$P<0,05$} \\
\hline
\end{tabular}

Góc cánh cẳng tay tại thời điểm kiếm tra xa, trung bình là $6,1^{0} \pm 4,8\left(-5,5^{0}-16.8^{\circ}\right)$ nhỏ hơn so với góc cánh cẳng tay trung bình bên lành, sự khác biệt có ý nghĩa thống kê (Kiểm định Wilcoson, $\mathrm{p}<0,05)$. So sánh ở từng lứa tuổi góc cánh cẳng tay đạt được thời điểm kiểm tra xa nhỏ hơn so với tay lành. Tuy nhiên góc cánh cẳng tay này vẫn là góc dương, tức là không còn biến dạng khuỷu vẹo trong.

Bảng 3.5. So sánh góc cánh cẳng taytrên X quang sau mố 6 tháng và thời điểm kiểm tra xa. $(n=52)$

\begin{tabular}{|c|c|c|}
\hline Nhóm tuối & Góc C-CT sau mố $\mathbf{6}$ tháng (độ) & Góc C-CT kiếm tra xa (độ) \\
\hline 6 tuối & $3,5 \pm 5,1(-3,5-8,5)$ Trung vị: 7,0 & $3,2 \pm 5,2(-4,0-8,6)$ Trung vị: 6,5 \\
\hline 7 tuối & $5,4 \pm 4,1(-3,0-9,0)$ Trung vị: 7,3 & $5,4 \pm 4,1(-3,5-9,0)$ Trung vị: 7,4 \\
\hline 8 tuối & $4,1 \pm 6,4(-5,0-10,0)$ Trung vị: 7,0 & $4,1 \pm 6,5(-5,5-10,0)$ Trung vị: 7,2 \\
\hline 9 tuối & $7,6 \pm 4,0(2,0-12,5)$ Trung vị: 6,5 & $7,8 \pm 4,0(2,4-12,5)$ Trung vị: 6,5 \\
\hline 10 tuối & $7,6 \pm 2,4(4,5-10,2)$ Trung vị: 8,0 & $7,5 \pm 2,3(4,5-10,2)$ Trung vị: 8,0 \\
\hline 11 tuối & $6,9 \pm 6,4(0,0-16,5)$ Trung vị: 8,0 & $7,3 \pm 6,3(0,5-16,8)$ Trung vị: 8,5 \\
\hline 12 tuối & $6,3 \pm 4,6(1,0-9,8)$ Trung vị: 8,0 & $6,4 \pm 4,6(1,2-10,0)$ Trung vị: 8,0 \\
\hline
\end{tabular}




\begin{tabular}{|c|c|c|}
\hline 13 tuối & $5,5 \pm 2,1(4,0-7,0)$ Trung vị: 5,5 & $5,4 \pm 2,3(3,8-7,0)$ Trung vị: 5,4 \\
\hline 14 tuối & $9,6 \pm 2,7(6,5-11,2)$ Trung vị: 11,0 & $9,5 \pm 2,5(6,6-11,0)$ Trung vị: 11,0 \\
\hline 15 tuối & $13,5^{0}$ & $13,5^{0}$ \\
\hline Giá trị trung bình chung & $6,1 \pm 4,8(-5-16,5)$ Trung vị: 7,0 & $6,1 \pm 4,9(-5,5-16.8)$ Trung vị: 7,0 \\
\hline & \multicolumn{2}{|c|}{$P>0,05$} \\
\hline
\end{tabular}

Số đo góc cánh cắng tay trung bình ở thời điểm sau mổ 6 tháng và khi kiểm tra xa khác nhau không có ý nghĩa thống kê (Kiểm định Sample T- test, $p>0,05)$. So sánh cặp ở từng nhóm tuổi, góccánh cẳng tay ở 2 thời điểm trên khác nhau không có ý nghĩa thống kê $(p>0,05)$.

\subsubsection{Kêt quả xa theo Ipollito}

Bảng 3.6. Phân loại kết quảchung theo Ipollito ( $n=52)$

\begin{tabular}{|c|c|c|}
\hline Kết quả chung & Số bệnh nhân & $\mathbf{\%}$ \\
\hline Tốt & 33 & 63,5 \\
\hline Khá & 14 & 26,9 \\
\hline Kém & 5 & 9,6 \\
\hline Tống & $\mathbf{5 2}$ & $\mathbf{1 0 0}$ \\
\hline
\end{tabular}

- Kiểm tra kết quả xa có $33 / 52$ BN $(63,5 \%)$ đạt kết quả tốt và 14/52 BN (26,9\%) đạt kết quả khá theo tiêu chuẩn của Ipollito (1990).

- Không có $B N$ nào có biến chứng tổn thương mạch máu, thần kinh.

\section{BÀN LUẬN}

Đầu dưới xương cánh tay ở trẻ em có những điểm cốt hóa và sụn tiếp hợp, những điểm này trong quá trình lớn lên của trẻ sẽ phát triển và gắn liền với thân xương. Sụn tiếp hợp ở đầu dưới xương cánh tay và các điểm cốt nhân sinh xương rất dễ bị ảnh hưởng trong chấn thương vùng khuỷu và phổ biến là gãy trên lồi cầu xương cánh tay.

Khuỷu vẹo trong (Cubitus varus deformity), là một di chứng thường gặp sau gãy trên lồi cầu xương cánh tay và các chấn thương có tổn thương sụn tiếp hợp ở vùng này ở trẻ em. Nguyên nhân là do rối loạn sự cốt hoá đâu dưới xương cánh tay làm cho lồi cầu và ròng rọc phát triển không đều nhau, lồi cầu ngoài thường phát triển mạnh hơn.

Biến dạng khuỷu veo trong thường ít ảnh hưởng đến chức năng vận động của khớp khuỷu nhưng một số nghiên cứu gần đây cho thây nếu để lâu có thể dẩn đến tổn thương liệt thần kinh trụ, bán trật khớp khuỷu và lỏng lẻo khớp [2], [5].

Do đó vấn đề điều trị sớm biến dạng khuỷu vẹo trong ngày càng được quan tâm nhiêu hơn. Phẫu thuật cắt xương ở trên lồi cầu xương cánh tay để chỉnh trục đang được áp dụng phổ biến hiện nay với nhiều cách cố định ổ cắt xương khác nhau như: găm đinh Kirschner, kết xương bằng khung cố định ngoài, kết xương căng dãn và kết xương nẹp vít.
Roach và CS cho rằng nếu ổ cắt xương không được cố định vững sẽ dẫn đến trượt 2 mặt cắt và dẫn đến mất kết quả chỉnh trục xương [2]. Có nhiều phương pháp cố định ổ cắt xương đã được áp dụng như bắt hai vít và buộc néo ép số 8 bằng dây thép như kỹ thuật của French, cố định bằng nẹp vít, đinh Kirschner xuyên chéo, cố định bằng khung cố định ngoài hoặc trước đây một số tác giả sau khi cắt xương chỉ bó bột.

Theo chúng tôi kỹ thuật cải biên của French để cố định vững chắc ổ cắt xương hình chêm bên ngoài trong điều trị biến dạng khuỷu vẹo trong có những thuận lợi nhất định. Thêm nữa, trong lúc mổ cho phép đánh giá về lâm sàng và kiểm soát được tình trạng di chuyển xoay và gập góc tốt hơn. Do đó phương pháp này đã giảm được tỷ lệ biến dạng tái phát. Với kỹ thuật này, chúng tôi đã bảo tồn được màng xương vì không lóc cốt mạc rộng và nhất là giữ nguyên được màng xương ở thành trong. Vì̀ vậy tại ổ cắt xương, điều kiện sinh học tại chỗ tổt hởn, ổ cắt xương liền nhanh hơn. Kinh nghiệm đã chỉ ra rằng yếu tố sinh học quyết định liền xương ổ gãy cũng quan trọng như yếu tố cơ học và cần phải duy trì cả 2. [2], [6]

Trong nghiên cứu của chúng tôi không gặp trường hợp nào bị liệt thần kinh trụ. Theo Sang và CS việc duy trì cố định vững chắc ổ cắt xương đến khi liền xương để tập vận động sớm là điều quan trọng nhất cần chú ý. Chúng tôi không đục gãy rời thành xương bên trongvà dùng 2 vít xương cứng bắt song song với hai cánh của hình chêm kết hợp buộc néo ép số 8 bằng dây thép để ép dần hai mặt cắt áp khít nhau, làm cho cố định vững chắc hơn, đồng thời sau mổ tăng cường máng bột trong thời gian 4 tuần, đủ cho hình thành can xương tại vị trí cắt xương. Nhờ vậy mà tất cả 63 bệnh nhẩn không có trường hợp nào mất kết quả nắn chỉnh. Kết quả nghiên cứu của bảng 3.5 cho thấy sử dụng phương pháp cố định này kết quả phẫu thuật chỉnh trục đạt được được duy trì cho đến khi ổ cắt xương liền chắc.

\section{KẾT LUẬN}

Chúng tôi cho rằng phương pháp French cải biên điều trị biến dạng khuỷu vẹo trong thật sự đơn giản, có thể chấp nhận được và cho hiệu quả điều trị tốt cả về thẩm mỹ và chức năng. 


\section{TÀI LIÊU THAM KHẢO}

1. Srivastava K.A., Srivastava1 D.C., Gaur S.C. (2008), Lateral closed wedge osteotomy for cubitus varus deformity.IJO - October - December 2008 / Volume 42 / Issue 4.

2. Roach J.W., Hernandez M.A. (1991). Corrective osteotomy for cubits vanis after Supracondylar fracture. J Paediatr Orthop 1991;14:187-91.

3. Ahmad I., Khan A., Idrees.M ( 2007). Modified French Osteotomy for cubitus varus deformity. Pakistan journal of Surgery, Volume 33, p270-272.
4. Ippolito E., Moneta M.R., D’Arrigo C. (1990). Post-traumatic cubitus varus. J BoneJoint Surg Am. 1990;72(5):757-765.

5. Ranjib K.J., Santosh T., Dhiraj S. (2019).Outcome of Corrective Dome Osteotomy for Cubitus Varus Deformity. Journal of Nobel Medical College,Volume 08, Number 02, Issue 15, July-December 2019, 42-46.

6. Kim H.T., Lee J.S., Yoo C.I.(2005) Management of cubitus varus and valgus. J Bone Joint Surg Am. 2005;87

\section{ĐẶC ĐIỂM LÂM SÀNG, CHẨN ĐOÁN ĐIỆN VÀ CÁC YẾU TỐ TIÊN LƯỢNG PHỤC HỒI TỔN THƯO'NG THẦN KINH QUAY}

\section{TÓM TẮT}

Mục tiêu:1) mô tả đặc điểm lâm sàng, chẩn đoán điện ở người bệnh tổn thương thần kinh quay giai đoạn sớm; 2) mồ tả các yếu tố tiên lượng phục hồi ở người bệnh tổn thương thần kinh quay giai đoạn sớm. Đối tượing và phương pháp: Nghiên cứu mồ tả cắt ngang trên 64 người bệnh được chẩn đoán tổn thương thần kinh quay giai đoan sớm tai bênh viên Hữu Nghị Việt Đức từ 1/2020 đển 12/2020. Kết quả: Tổn thương tại cánh tay chiếm $57,8 \%, 29,7 \%$ số ca có hiện tượng nghẽn dẩn truyền thần kinh. Tỷ lệ có phục hồi chức năng thần kinh là $71,9 \%$. Kết luận:Triệu chứng lâm sàng và điện chẩn cơ trong tổn thương dây thần kinh quay rất đa dạng, phụ thuộc vào vị trí, thời gian và hình thái tổn thương. Dây thần kinh quay có tiên lượng phục hồi tốt, có liên quan tới thời gian phát hiện và điều trị, hình thái tổn thương và dấu hiêu trên điền chẩn cớ.

Tư khoá: Điên sinh lý thần kinh, tổn thương thần kinh quay, liệt thẩn kinh quay.

\section{SUMMARY}

\section{CLINICAL, ELECTROPHYSIOLOGY AND THE RECOVERING PROGNOSTIC FACTORS IN RADIAL NERVE PALSY}

Objectives: 1)Describe the clinical and electrophysiology characteristics of the early radial nerve palsy. 2) Describe the recovering prognostic factors in radial nerve palsy. Subjects and method: A cross-sectional descriptive study on 64 patients diagnosed with radial nerve palsy at Viet Duc university Hospital from 1/2020 -12/2020. Results: Injury to the arm accounts for $57.8 \%, 29.7 \%$ of cases

\footnotetext{
${ }^{1}$ Bệnh viện Hữu Nghị Việt Đức

${ }^{2}$ Trường Đại học Y Hà Nội

Chịu trách nhiệm chính: Lê Quốc Việt

Email: leviet11051989@gmail.com

Ngày nhận bài: 24/4/2021

Ngày phản biện khoa học: 18/5/2021

Ngày duyệt bài: 12/6/2021
}

Lê Quốc Việt ${ }^{1}$, Phạm Đức Hiếu ${ }^{1}$, Đồng Ngọc Minh ${ }^{1}$, Nguyễn Anh Tuấn ${ }^{1,2}$ have neurotransmitter obstruction. The rate of neurological rehabilitation is $71.9 \%$. Conclusions:The clinical and electrodiagnostic symptoms of radial nerve injury are variety, depending on the location, duration and morphology of the lesion. The radial palsy nerve has a good prognosis for recovery, related to detection and treatment time, lesion morphology and electromyographic signs.

Key words: Electroneurophysiology, radial injury, radial nerve palsy.

\section{I. ĐĂT VẤN ĐỀ}

Thần kinh quay có đường đi dài, quanh co và đi gần thân xương cánh tay nên thường bị tổn thương. Tổn thương thần kinh quay có thể xảy ra ở bất cứ điểm nào trên đường đi dây thần kinh và nguyên nhân cũng rất khác nhau [1]. Chẩn đoán dựa trên thăm khám lâm sàng, chẩn đoán điện và $X$ - quang để xác định vị trí và mức độ tổn thương. Tổn thương thần kinh chia thành ba loại: mất thực dụng thần kinh (neurapraxia); tổn thương sợi trục (axonotmesis); tổn thương thần kinh (neurotmesis) [2]. Điều tri bảo tồn có thể hiệu quả ở $70 \%$ trường hợp liệt thần kinh quay cao [3].

Phục hồi thần kinh phụ thuộc vào nhiều yếu tố như tuổi, giới, thời gian, phương pháp điều trị, hình thái tổn thương...[4]. Do đó chúng tôi tiến hành nghiên cứu với mục tiêu: 1) Mô tả đặc điểm lâm sàng, chẩn đoán điện ở người bệnh tổn thương thần kinh quay giai đoạn sớm. 2) Mô tả các yếu tố tiên lượng phục hồi ở người bệnh tổn thương thần kinh quay giai đoạn sớm

II. Đốl TƯỢNG VÀ PHƯƠNG PHÁP NGHIÊN CỨU

1. Đối tượng nghiên cứu. Gồm các bệnh nhân bị tổn thương thần kinh quay giai đoạn sớm tại Bệnh viện Hữu Nghị Việt Đức từ 1/2020 $-12 / 2020$. 